\title{
O USO DA GEOTECNOLOGIA PARA IDENTIFICAÇÃO DE LOCI DEPOSICIONAIS NA SERRA DA BARRIGA, ALAGOAS
}

\author{
Laís Susana de Souza Gois ${ }^{(a)}$, Kleython de Araujo Monteiro ${ }^{(b)}$ \\ (a) Igdema, Universidade Federal de Alagoas, laisgois15@gmail.com \\ (b) Igdema, Universidade Federal de Alagoas, geokleython@gmail.com
}

Eixo: Geotecnologia e Modelagem Espacial em Geografia Física

\begin{abstract}
Resumo
Este artigo objetiva mostrar o uso da geotecnologia para identificação de loci deposicionais ou depositos quaternários na Serra da Barriga, Alagoas, que segundo alguns autores como Bigarella, são os melhores indicadores para os estudos paleoclimáticos, pois guardam os indícios de como climas anteriores contribuíram para modificação da paisagem. Para o desenvolvimento do trabalho foram utilizados dados exportados de GPS, imagens de satélite e o cruzamento de dados em ambiente GIS utilizando o método de krigagem para criação de um Modelo Digital do Terreno (MDT). Posteriormente, foi elaborada a direção dos fluxos de sedimentos atuais na paisagem, possibilitando a identificação de loci deposicionais atuais. Foram identificados 22 possíveis loci deposicionais que auxiliarão na otimização do trabalho de campo para identificação e coleta de material dos mesmos visando contribuir para uma futura reconstrução paleoambiental da área.
\end{abstract}

Palavras chave: Serra da Barriga; loci deposicionais; paleogeografia;

\section{Introdução}

O estudo da paleogeografia está na relação tempo-espaço, pois é de extrema importância saber a estrutura dos paleoambientes da Terra nos diferentes períodos de tempo, assim comparando-os para entender os processos formadores da dinâmica da paisagem.

Ao longo do tempo cientistas buscam explicar determinados fenômenos para aperfeiçoar o conhecimento existente sobre os processos transformadores da paisagem. Dentro desses fenômenos podemos considerar os loci deposicionais como estruturas fundamentais para este aperfeiçoamento (BIGARELLA, 2003). Nos loci podem ocorrer ou não o deposito de sedimentos. Tendo ocorrido à deposição de sedimentos, os mesmos contribuirão para esclarecer os processos físicos e químicos atuantes em determinado porção do relevo. Hoje para a identificação e análise dos loci deposicionais podemos utilizar as geotecnologias como ferramenta facilitadora. Esta nos proporciona condições técnicas mais eficazes, tornando possível conhecer melhor o local escolhido para pesquisa, a fim de não tomar decisões inadequadas e diminuir o tempo gasto para ela.

No caso desta pesquisa esta ferramenta foi utilizada para a identificação de loci deposicionais na Serra da Barriga localizada no município de União dos Palmares - AL. 


\section{O Quaternário e os Loci Deposionais}

O Quaternário é dividido em duas épocas, Pleistoceno e Holoceno. Umas das principais características do Quaternário é a grande ocorrência de variações climáticas, alternando entre períodos glaciais e interglaciais. Esse processo de variação de temperatura promoveu alterações no regime de precipitações e consequentemente na cobertura vegetal, ocasionando erosão e deposição de materiais quando da transição entre o período mais seco e a retomada ao mais úmido. Alguns destes materiais depositados ficaram armazenados possibilitando o estudo das mudanças da cobertura superficial da paisagem (ARRUDA, 2004).

Estes depósitos sedimentares demandam que um espaço de acomodação exista ao longo da encosta ou no seu sopé, e que a energia do sistema não seja suficiente para que tal material não possa ser removido, preservando assim a informação sedimentar. Estes espaços de acomodação são conhecidos como loci deposicionais (MELO, 2014).

Os depósitos são formados a partir de processos erosivos e de agradação, podendo ser aluviais, contendo material oriundo de rios, eluviais, constituindo o topo das cristas e coluviais constituídos de materiais acumulados nas encostas. O colúvio pode ser encontrado em reentrâncias na encosta e no sopé da mesma. Independente do seu tipo, através destes depósitos é possível esclarecer mudanças climáticas ocorridas ao longo do tempo, mudanças essas que contribuíram diretamente para a atual estrutura do relevo (ARRUDA, 2004).

Bigarela (2003), afirma que uma vez comprovada a importância das mudanças climáticas cíclicas como fator controlador da evolução da paisagem, ter-se-iam os elementos fundamentais para a interpretação e datação das diferentes formas de relevo. Para a presente pesquisa o foco é o ambiente de encosta, no qual podemos encontrar, com o auxílio das geotecnologias, os espaços de acomodação necessários para a localização dos depósitos coluviais.

\section{A Serra da Barriga}

No que se refere a este trabalho o objetivo foi identificar os loci deposicionais na Serra da Barriga (Figura 1), localizada no município de União dos Palmares. Esta estrutura faz parte do Macrodomo da Borborema, mais especificamente do compartimento Cimeira Estrutural Pernambuco-Alagoas, caracterizado por Correa (et al, 2010) com possuindo ocorrência de complexos gnáissico-migmatitícos e extensos lineamentos estruturais.

Na Serra da Barriga localizou-se o Quilombo dos Palmares - maior e mais duradouro da América serviu como refúgio para milhares de negros escravizados tanto na dominação portuguesa quanto na holandesa no período colonial. Estima-se que cerca de 20 mil pessoas viveram no local entre 1597 a 


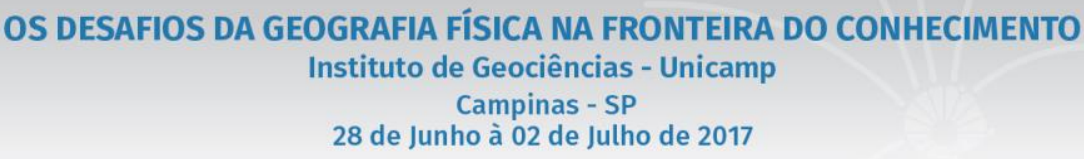

1695, entre elas destaca-se a figura de Zumbi dos Palmares considerado herói negro símbolo da resistência a escravidão no Brasil (PALMARES, 2017).

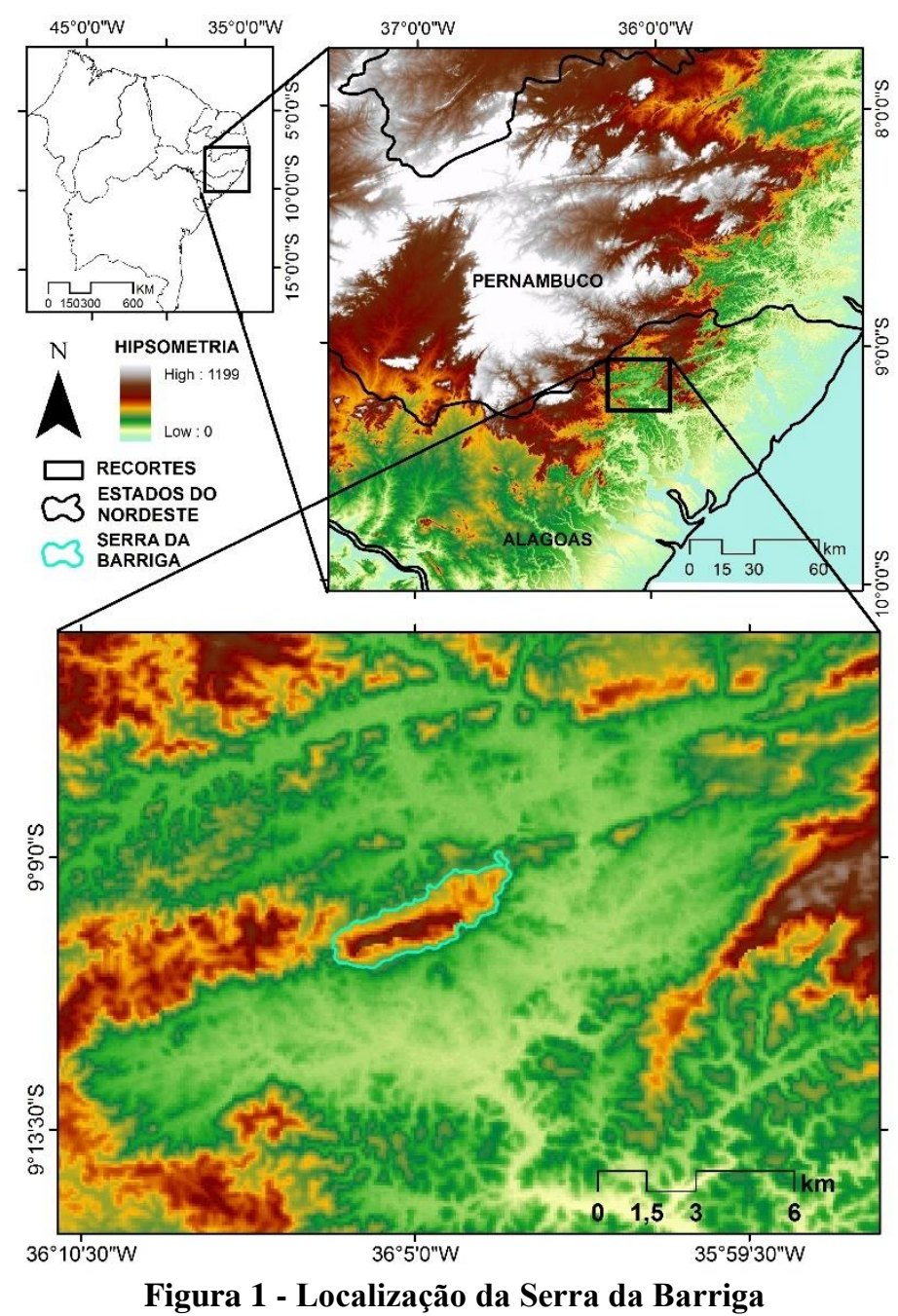

\section{Métodos}

Para obtenção dos modelos foram utilizados dados XYZ do projeto SRTM (Shuttle Radar TopographicMission) trabalhados em ambiente GIS, utilizando o método de krigagem para elaboração do Modelo Digital do Terreno (MDT).

Após a criação do MDT foram obtidos vetores de fluxo gerados a partir de ferramentas de direção de fluxo, interpretados como sendo o destino de transporte dos sedimentos. Esses vetores são desenvolvidos a partir da interpolação matemática de dados de altimetria onde os fluxos partem de valores mais elevados para valores menos elevados. 
XVII Simpósio Brasileiro

de Geografia Fisica Aplicada

I Congresso Nacional

de Geografia Física

\section{OS DESAFIOS DA GEOGRAFIA FÍSICA NA FRONTEIRA DO CONHECIMENTO \\ Instituto de Geociências - Unicamp \\ Campinas - SP \\ 28 de Junho à 02 de Julho de 2017}

As áreas de concentração terminal dos fluxos são interpretadas como sendo possíveis loci deposicionais, ou seja, setores na encosta onde ocorrem espaços de acomodação para armazenamento das corridas de sedimentos (MONTEIRO et al, 2008).

\section{Resultados}

Foram identificados 22 loci deposicionais (Fig. 2). Estes espaços de acomodação de sedimentos podem possuir informações sedimentares preciosas para a reconstrução paleoambiental da região da Serra da Barriga.
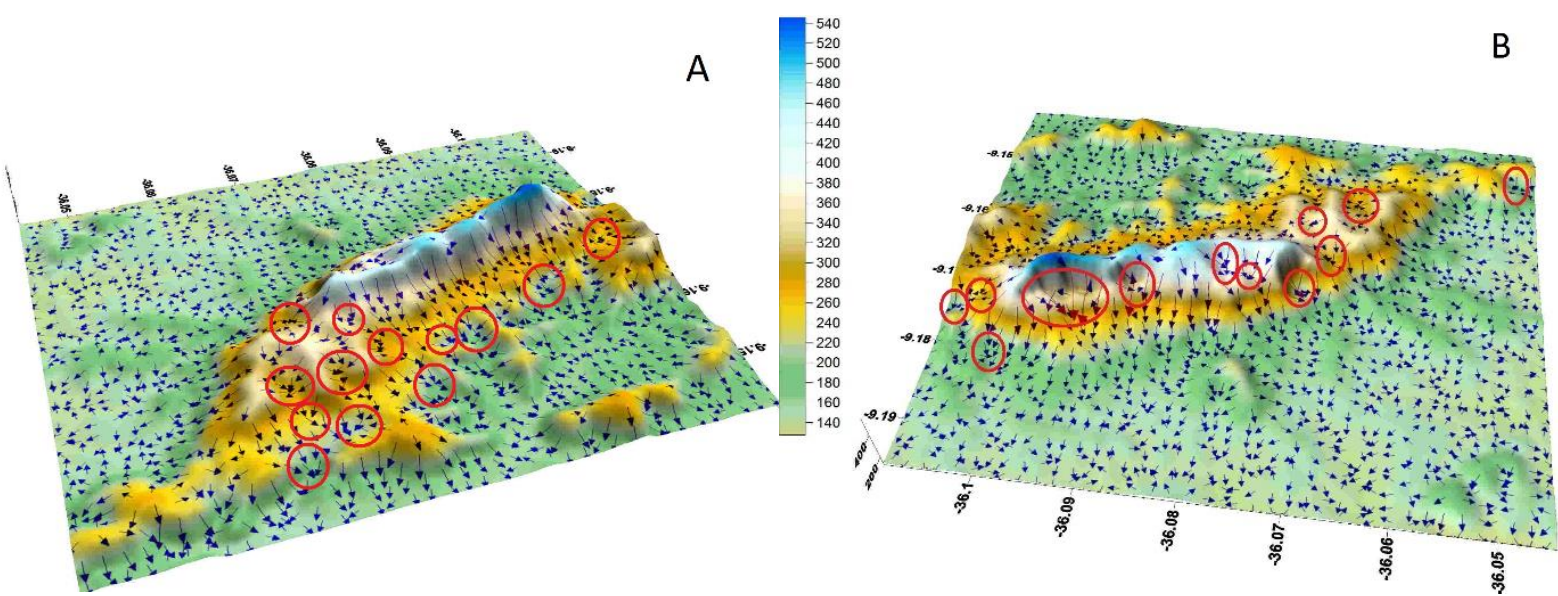

Figura 2 - Modelo Digital do Terreno (MDT) com a localização dos possíveis loci deposicionais. A - Vista da Face Norte; B - Vista da Face Sul.

$\mathrm{Na}$ face Norte da Serra da Barriga foram encontrados 12 possíveis loci deposicionais, enquanto na face Sul foram identificados 10. Alguns destes podem ser identificados em ambos pontos de vista.

Para dar sequência a pesquisa serão realizadas visitas a campo para verificar a condição atual dos loci encontrados através do MDT, ou seja, verificar se há pacotes de sedimentos depositados. Caso tenha ocorrido, daremos início a reconstrução paleoambiental da Serra da Barriga partindo da análise destes depósitos.

\section{Conclusões}

A aplicação de ferramentas geotecnológicas aliadas ao conhecimento já produzido sobre a dinâmica da paisagem permite uma melhor análise do relevo e sua estrutura, contribuindo assim com a otimização da pesquisa, reduzindo tempo e custos em campo e propiciando uma melhor visualização, em diferentes escalas, dos compartimentos morfológicos. 
Desta forma, verificou-se que a aplicação deste método foi eficiente quanto ao objetivo de identificar os espaços de acomodação existentes na Serra da Barriga. Estes espaços identificados, também chamados de loci deposicionais, possibilitarão a identificação em campo dos depósitos que permitirão análises sedimentológica e estratigráficas, permitindo posteriormente uma reconstrução paleogeográfica da região.

\section{Bibliografia}

ARRUDA, E. Caracterização dos ambientes deposicionais na bacia do ribeirão entupido, complexo alcalino do Passa Quatro, estado de São Paulo. 2004. 174 f. Dissertação (Mestrado em Geografia) - Instituto de Geociências e Ciências Exatas, Universidade Estadual Paulista, Rio Claro -SP, 2004.

BIGARELLA, J. J. et al. Estrutura e origem das paisagens tropicais e subtropicais. Florianópolis: Editora da UFSC, Volume 3. 2003.

CORREA, A. C. B.; TAVARES, B. DE A. C. ; MONTEIRO, K. A. ; Cavalcanti, L. C. S. ; LIRA, D. R. . MEGAGEOMORFOLOGIA E MORFOESTRUTURA DO PLANALTO DA BORBOREMA. Revista do Instituto Geológico, v. 31, p. 35-52, 2010.

MELO, R. F.T. Evolução dos depósitos de encosta no leque Malaquias e lagoa das pedras no entorno do maciço estrutural da Serra de Água Branca. 2014. 155 f. Dissertação (Mestrado em Geografia) - Centro de Filosofias e Ciências Humanas, Departamento de Geografia, Universidade Federal de Pernambuco, Recife, 2014.

MONTEIRO, K. A.; SIVA, H. A. ; LIMA, C. S. ; BARROS, A. C. M. . IDENTIFICAÇÃO DE LOCI DEPOSICIONAIS COMO CONTRIBUIÇÃO PARA A COMPREENSÃO DA DINÂMICA EVOLUTIVA DA PAISAGEM NA ÁREA DE NAZARÉ DA MATA PERNAMbUCO E SEU ENTORNO. Geografia. Ensino \& Pesquisa (UFSM), v. 12, p. 4040, 2008

PALMARES. Serra da Barriga. Disponível em: http://serradabarriga.palmares.gov.br/?page id=96. Acesso em: 21 Jan. 2017 